\title{
The Evolution of Resilience
}

\section{Peter Rogers}

Macquarie University, Australia, https://www.mq.edu.au/

\begin{abstract}
The concept of resilience has roots in many disciplines, making the pursuit of a unified theory very attractive but also very difficult. Yet this has not stopped scholars and politicians from attempting to claim resilience as their flagship concept and build a canon for the 21st century around it. This tendency to reduce or totalize resilience has spawned a host of taxonomies, each seeking to offer the final word on the definitional debate. I argue that this desire to create a unified theory of resilience misapplies the concept, ignores the dynamics of its emergence and the polysemic nature of its use in theory, policy, and practice. This malleability makes resilience at once both a very attractive logic for dealing with uncertainty and a dangerous pathway towards embedding untempered algorithmic systems of coercive prediction into the governance of everyday life. In understanding the emergence of the resilience concept, one must appreciate both the positive and negative potential of this flexible and adaptive notion. I close by suggesting that resilience has gained such traction in recent years in no small part because it represents a shift in the onto-politics of our time, but that we must be careful about which type of resilience gets enacted.
\end{abstract}

Keywords: resilience, assemblage, post-structuralism, positive critique, problematization.

\section{Introduction}

The concept of resilience has roots in many disciplines, making the pursuit of a unified theory very attractive but also very difficult. The term reappears in many different fields of study and diverse policy portfolios, each with its own dead ends, boundaries, and bridges to be built and debated. ${ }^{1}$ If we attempt to under-

1 Simin Davoudi, "Resilience: A Bridging Concept or a Dead End?" Planning Theory \& Practice 13, no. 2 (2012): 299-307. 
stand this concept in terms of contemporary problems, we must first map articulations of that problem through its antecedents to better disturb our concept in the present. In doing so, the concept of resilience is to be problematized with nuance, highlighting problems in how we have approached it previously and are approaching it now. I argue that approaching resilience as an 'institution' of governance allows researchers to better unpack how diverse forms of resilience are reshaping the incentives and constraints on human conduct. The often pessimistic critique of resilience as biopolitics and neoliberalism has not slowed the spread of resilience, only deepened the distance between critical theory and policy. A productive, positive critique using elements of assemblage thinking and a vernacular of new institutional economics allows us to better test how acceptance and enactment of resilience empower, or demand, a rethinking of the contractual relations underpinning social order. I will explore the critique of resilience, point out several limitations, and highlight where contributions are opening up new possibilities for a more constructive engagement. If a broader ontological shift in the foundations of liberal politics is emerging rather than attempting to identify the singular point of critique within a new 'model' of social order, resilience may be better approached as part of an 'interregnum'; which traditional forms of governance and traditional forms of critique are both illequipped to explain. I argue that by crossing the divide between traditions of poststructural critique and new institutionalist economics, we can find a common vernacular to explain how diverse articulations of resilience are shaping the conditions of possibility for social order, but many of our traditional assumptions on the stability of a liberal 'modern' ontology may require revision. Beyond a 'simple' problematization of resilience, a more nuanced and positive critique will likely be required for the social sciences to remain relevant in shaping the institutional form of resilience as it emerges. ${ }^{2}$

\section{A Critical Concept and a Concept to Critique}

It is now widely acknowledged that the resilience concept has a rich etymological past, emerging in the English language via Francis Bacons "Sylvara Sylvarum." 3 Bacon explored the asymmetries between human sensibility and the intricacy of natural forces, mentioning resilience only in passing as an action of bouncing back via the repercussive "resilience of echoes." " It was later used in engineering to describe the obdurate qualities of building materials, evoking elasticity and

2 David Garland offers a particularly useful insight into this framing of Foucauldian genealogy around the history of the present. This research offers one approach to repackaging those tools through a more creative engagement beyond the limits of currently understood post-structuralist doctrine. See David Garland, "What Is a "History of the Present"? On Foucault's Genealogies and Their Critical Preconditions," Punishment \& Society 16, no. 4 (2014): 365-384, https://doi.org/10.1177/1462474514541711.

3 Francis Bacon, Sylva Sylvarum, or, A Natural History in Ten Centuries (London: William Lee, 1657).

4 Bacon, Sylva Sylvarum, 330. 
resistance in wooden and steel beams. ${ }^{5,6}$ It has been used to narratively express a characteristic of human perseverance and in developmental psychology enhanced empirically as an integrative framework for investigating the adaptive capabilities of the human mind. ${ }^{7}$ This internalizes resilience but renders it a productive immanence by addressing unexpectedly positive adaptations or recoveries after exposure to adversity. ${ }^{8}$ Perhaps the most influential reading of resilience is drawn from complex social and ecological systems (SES) theory. ' ${ }^{\text {'To walk }}$ back' became analogous with recovery time after a disturbance ${ }^{10}$ but was later developed into resilience as a complex systemic panarchy. ${ }^{11}$

Repurposing elements of creative-destruction in economic theory, panarchy informs understanding the social and ecological as interdependent systems with adaptive cycles of growth, collapse, and reorganization with potential to create a new "metastable equilibrium," then subject to its own adaptive cycles. Perhaps presciently, Holling and Gunderson brought human and ecological interdependency into focus directly and empirically, a precursor to current readings of complexity in the Anthropocene. By engaging with the complexity of time, space, and scale across diverse and non-complementary systems, social-ecology made a unique contribution to the emerging discourse of resilience. It empowered an instrumental reading of resilience as the capacity of complex interdependent systems to absorb disruptions and "walk back" to stability, informing over a decade of reform in governing of disasters as a cycle of anticipation, assessment, mitigations (often encompassing elements of preparedness and prevention), response and recovery. It also opened a door for incorporating economic and ecological philosophy via the positive cycles of revolt and remembering empowering creative-destruction to potentially transform a system, i.e., create a new normal past the tipping point. This presentation of complex systems allows for a reading

5 On the early $19^{\text {th }}$ Century works of Thomas Young see Alasdair N. Beal, "Thomas Young and the Theory of Structures 1807-2007," The Structural Engineer 85, no. 23 (2007): 43-47.

6 Thomas Tredgold, "XXXIV. On the Medulus of Elasticity of Air, and the Velocity of Sound," The Philosophical Magazine 52, no. 245 (2018): 214-216, https://doi.org/ 10.1080/14786441808652035.

7 Ann S. Masten, "Resilience in Development: Implications of the Study of Successful Adaptation for Developmental Psychopathology," in The Emergence of a Discipline: Rochester Symposium on Developmental Psychopathology, ed. Dante Cicchetti, vol. 1 (Hillsdale, NJ: Erlbaum, 1989), 261-294.

8 Ann S. Masten, "Resilience in Developing Systems: Progress and Promise as the Fourth Wave Rises," Development and Psychopathology 19, no. 3 (2007): 921-930.

9 C.S. Holling, "Resilience and Stability of Ecological Systems," Annual Review of Ecology and Systematics 4, no. 1 (1973): 1-23, https://doi.org/10.1146/annurev.es.04.1101 73.000245.

10 Lance Gunderson and Carl Folke, "Resilience-Now More Than Ever," Ecology and Society 10, no. 2 (2005): 22, http://www.ecologyandsociety.org/vol10/iss2/art22/.

11 Lance H. Gunderson and C.S. Holling, eds., Panarchy: Understanding Transformations in Human and Natural Systems (Washington, DC: Island Press, 2002). 
of "meta-stable equilibrium" as an ongoing process of change, opposing the assumption that civilization can be held in an optimal "steady state" - as per the requirements of a "just in time" model of mass production. Read through resilience, such systems become fragile, easy to disrupt, and thus more vulnerable to negative effects should a disruption occur. Surface tension begins to appear here between the positive potential for transformative change and the need to remember and maintain the current system forms and function. When we translate this ideational framework from systems ecology into the realm of politics and governance, these tensions are exacerbated as practitioners are forced to operationalize the abstract logic within the adherent bounds of their organizations' traditional patterns of policy generation and implementation. It can be argued that the organizational path dependency in the late Holocene ${ }^{12}$ is broadly aligned to the illusory "automatic balancing" of the market-driven by discourses of risk and growth-rather than the distribution of democratic public goodsdriven by discourses of rights, freedoms, and access to privileges. This increasingly places exorbitantly instrumental requirements upon practitioners to "solve the problem" in a cost-effective and risk-averse manner, often drawn by "thirdway" managerialism into a quantitatively evaluated system optimization to meet performance quotas, even in the face of oversimplified 'aleatory' (unreducible natural randomness) or 'epistemic' uncertainties (lack of or unreliability of data). ${ }^{13}$ In such conditions, resilience proves elusive to define, impossible to address in a holistic manner and appears woven into the fabric of existing problems, perhaps even deepening them further. ${ }^{14}$

These multiple articulations lead to the presentation of resilience as 'polysemous,' emergent and contested, difficult to reduce to a singular canonical definition. ${ }^{15}$ As the limits of the concept are permeable so has it been rendered amenable to a broad suite of, sometimes contradictory, applications within governance. As a "traveling concept," it has rhizomatically ${ }^{16}$ appeared across diverse

12 Dryzek elaborates upon these path dependencies using a broader traditional reading of institutions. John S. Dryzek, "Institutions for the Anthropocene: Governance in a Changing Earth System," British Journal of Political Science 46, no. 4 (2016): 937-956.

13 Gianluca Filippia, Massimiliano Vasile, Daniel Krpelik, Peter Zeno Korondi, Mariapia Marchi, and Carlo Poloni, "Space Systems Resilience Optimisation under Epistemic Uncertainty," Acta Astronautica 165 (2019): 195-210.

14 David Chandler, "The End of Resilience? Rethinking Adaptation in the Anthropocene," in Resilience in the Anthropocene: Governance and Politics at the End of the World, ed. David Chandler, Kevin Grove, and Stephanie Wakefield (London: Routledge, 2020), 5067.

15 Magali Reghezza-Zitt, Samuel Rufat, Géraldine Djament-Tran, Antoine Le Blanc, and Serge Lhomme, "What Resilience Is Not: Uses and Abuses," Cybergeo: European Journal of Geography (2012), 621, https://doi.org/10.4000/cybergeo.25554.

16 This draws on a similar logic to that of "surveillant assemblages" as discussed by Sean Hier, where expansion of resilience, similar to late-modern surveillance, enables significant transformations 'in the purpose and intention' of resilience practices and the operation of nested hierarchies. The intensification of resilience assemblages, in a similar way, informs processes of resilience that produce social control rather than the 
policy portfolios, ${ }^{17}$ and the politics of resilience as governance has been subject to much debate. More attention is paid to "optimising the inherent capacity of valued systems to withstand, absorb and bounce back from crisis" through the lens of security ${ }^{18}$ than to the correlations between cognition, beliefs, and values at the level of its enactment amongst individual citizen-subjects. The strategic view gives us insight into resilience, but this approach tends to skew that any reading of the morality of resilience to one aligned with the broader ongoing critique of neoliberalism as a system of rule.

Where this approach addresses the subject, the "resilient subject" is couched within "the necessity and positivity of human exposure to danger" as the central driver of becoming more resilient. Yet even here, this narrow view of values implies that resilient growth only results from exposure to dangerous trauma and that government is failing to provide a promise of security, tied to a liberal ontology of state-citizen relationships. This fails to incorporate the possibility of encounters that result in resilient growth from the manifestation of prosocial capacities, e.g., not panicking, generosity, solidarity, and altruism. Such enactments of prosocial emotions are important in creating a feeling of purpose in life and inform the adoption of a prosocial personal moral compass. ${ }^{19}$ This opens a configuration of self that allows for a broader interplay-between system and self-where "the assertive, disengaged self who generates distance from its background (tradition, embodiment) and foreground (external nature, other subjects) in the name of an accelerating mastery of them ${ }^{20}$ is coerced or incentivized to become more resilient in thought and deed.

At the cognitive level, resilience informs our expectations of each other and organizations (which we are a part of or interact with) at the onto-political level as enacted beliefs. Yet this is tricky to navigate as it blurs traditional distinctions-such as subject-object and praxis-poiesis-central to the critique of the rationalist, modern project. Such critique unfurls resilience as a dispositif of governance, a loose "system of correlation," and an ad hoc totality irreducible to a

implied democratization of the ordering logic underpinning its rhetoric. Sean P. Hier, "Probing the Surveillant Assemblage: On the Dialectics of Surveillance Practices as Processes of Social Control," Surveillance \& Society 1, no. 3 (2003): 399-411, https://doi.org/10.24908/ss.v1i3.3347.

17 Peter Rogers, Jim J. Bohland, and Jennifer Lawrence, "Resilience and Values: Global Perspectives on the Values and Worldviews Underpinning the Resilience Concept," Political Geography 83 (2020), 102280, https://doi.org/10.1016/j.polgeo.2020.102 280.

18 Chris Zebrowski, The Value of Resilience: Securing Life in the Twenty-first Century (London: Routledge, 2015), p. 147, emphasis added.

19 Brian M. Iacoviello and Dennis S. Charney, "Psychosocial Facets of Resilience: Implications for Preventing Posttrauma Psychopathology, Treating Trauma Survivors, and Enhancing Community Resilience," European Journal of Psychotraumatology 5, no. 1 (2014), 23970, https://doi.org/10.3402\%2Fejpt.v5.23970.

20 Stephen K. White, "Weak Ontology and Liberal Political Reflection," Political Theory 25, no. 4 (1997): 502-523, quote on p. 503. 
mere expression of sovereign power. ${ }^{21}$ The critique of the resilience dispositif argues that, on the one hand, its decentralized conceptual nature denies the critical 'left' of the modernist political project a solid ground from which to destabilize it and, an the other hand, that it appears amenable to co-option by the increasingly neo-liberalizing path dependencies of contemporary governance. ${ }^{22}$ Yet without embracing the cognitive potential for positive outcomes from resilience, the conceptual ground under the concept appears ever-shifting, as are the value-laden meanings and applications that emerge from each encounter in situ. This impacts the epistemology of enactment through which a resilient citizensubject is conceived, governed and the complementary or contested incentive structures legitimized and/or enacted in the name of "resilience as governance." As "potential imaginaries of resilience - as a policy-making "magic bullet" for problems as diverse as underdevelopment, conflict and environmental crises," 23 resilience has continued to grow in scope and gain wider traction in the policy. As such, I argue that these imaginaries-emerging with and through "resilience as governance"-may herald the rise of an emergent institution.

\section{Resilience as Institutionalized in Governance}

At times, resilience has come to appear easily deployed as a "quasi-universal answer to the problems of government." ${ }^{24}$ Any such "quasi-universal" concept must have significant repercussions not just for the process of governing but also on what is being governed, who is being governed, and how that governance is enacted. When encountered in this way, resilience has the potential to become a significant influence on political, economic, and social incentive structures, designed into resilient forms of governing. To make a case for the institutionalization of resilience more plainly, one should test the contractual relationships underwriting the nature of change it engenders. Resilience is at heart a collaboration strategy operating within the path dependencies of a competition-driven configuration of governance. How collaborative practices emerge, and are incentivized, should indicate more clearly the nature of any shift in the underpinning contractual relationship between key players, such as citizen-subject, 'market' and 'state.'25

21 Bruce P. Braun, "A New Urban Dispositif? Governing Life in an Age of Climate Change," Environment and Planning D: Society and Space 32, no. 1 (2014): 49-64, https://doi.org/10.1068/d4313.

22 Chandler, "The End of Resilience?"

23 Chandler, "The End of Resilience?" p. 81.

24 Claudia Aradau, "The Promise of Security: Resilience, Surprise and Epistemic Politics," Resilience 2, no. 2 (2014): 73-87, https://doi.org/10.1080/21693293.2014.914765, quote on p. 73.

25 One can draw on Stiglitz to reflect more on the intertwining of state and market, for example the tensions in separating production from finance through regulation and the importance of government regulation with regard to financial systems. Joseph $\mathrm{E}$. 
A key concern is to unveil if and how "resilience as governance" alters the articulation of contractual relationships between citizen-state-market. Another is to understand the value-shift implied by "ontological drift" in the institutional arrangements underpinning social order. Yet another is to align the change in beliefs to values to the operationalization of legitimate forms of governance through resilient ways of working. The preliminary work undertaken throughout the remainder of this article opens up a different approach for future research, but we must first rethink present uses of resilience more carefully. This helps to illustrate better the ordering logic of contractual relationships so implied by the emergence of resilience, as well as drawing attention to the need to understand shifting institutions emerging within a drifting onto-politics - to which we will return below. One might suggest that the wide deployment of resilience in governance locates this way of thinking and working on the fast track to becoming 'institutionalized' both as core business and logic of governance, reshaping what Douglas North has called "the rules of the game" but more evidence is needed to know what trajectory this implies for social order. ${ }^{26}$ To test this proposition, one can draw on the resilient governance strategies that have been enacted in mitigating crises in recent years.

Increasingly policymakers have emphasized resilience as both a process of governing and as a suite of practical and pragmatic design initiatives driven by a blend of security, disaster, and crisis management but spanning many departments and portfolios. ${ }^{27,28,29} \mathrm{In}$ a post-9/11 world, the need to "become more resilient" has been readily accepted as a generalized public good in policy terms but criticized for offering an uninspiring political vision unsuitable for realizing the change it purports to deliver. ${ }^{30}$ High profile and globally impactful crises have

Stiglitz, "Markets, States and Institutions," Roosevelt Institute, June 22, 2017, https://rooseveltinstitute.org/publications/markets-states-and-institutions/.

26 In this sense, North, Wallis, and Weingast treat institutions not as 'groups' or 'organizations' which function as coalitions of actors with a common interest, instead they specify institutions as processual in nature as: "the patterns of interaction that govern and constrain the relationships of individuals. Institutions include formal rules, written laws, formal social conventions, informal norms of behaviour, and shared beliefs about the world, as well as the means of enforcement." Douglass C. North, John Joseph Wallis, and Barry R. Weingast, Violence and Social Orders: A Conceptual Framework for Interpreting Recorded Human History (Cambridge: Cambridge University Press, 2009), 15.

27 John Auerbach and Benjamin F. Miller, "Deaths of Despair and Building a National Resilience Strategy," Journal of Public Health Management and Practice 24, no. 4 (2018): 297-300, https://doi.org/10.1097/PHH.0000000000000835.

28 Christian Fjäder, "The Nation-State, National Security and Resilience in the Age of Globalisation," Resilience 2, no. 2 (2014): 114-129, https://doi.org/10.1080/216932 93.2014.914771.

29 David Omand, “Developing National Resilience," The RUSI Journal 150, no. 4 (2005): 14-18, https://doi.org/10.1080/03071840508522884.

30 Kate Driscoll Derickson, "Resilience is not Enough," City 20, no. 1 (2016): 161-166, https://doi.org/10.1080/13604813.2015.1125713. 
diversified this discourse even further. The result has been the emergence of more instrumentalist pragmatism in public policy, focusing on practical capabilities and the needs of practitioners in critical areas of work: such as risk management, supply-chain management, sustainable urban development, critical infrastructure protection, and disaster risk reduction. International organizations, governments, and firms increasingly have resilience strategies or strategic goals for building resilience, and in each case, resilience is interpreted with subtle difference. Combined with rhetorical calls for resilience or salutations to the resilience of the people or nation following crisis events, the idea of resilience and being resilient is, today, firmly established in the common, conceptual and political vernacular of our times. Resilience does not manifest as an explicit totalizing dispositif of governance, but as nested assemblages of both human and non-human interactions encountered in different configurations at points of strategic orientation. These encounters serve as points from which the skills and resources for a targeted action can be mobilized, guided by best practice principles and toolkits in each experiment but not as a universal model. As such, it reconfigures the contractual relationships and expectations between individuals and organizations. By analyzing complementary rules and practices, we should therefore address resilience as an institution of governance in more depth.

In the cycle of adaptive crisis management, this has manifested as a guiding principle for developing the capabilities of specific organizations to act on particular risks, hazards, or threats. It also informs the perceived capacity of the social order to maintain a robust and healthy function in the face of existential uncertainty or explicit crises. However, resilient governance is not isolated in a black box within 'politics.' A concurrent surge in the discussion of economic and organizational forms of resilience has emerged in the private sector, with subtle but significant influence in the broader adoption of quality standards for resilient ways of working at the individual and organizational level. ${ }^{31}$ This has also been a contributor to the growth of philanthropic organizations' engagement in resilience building efforts where existing organizational practices can stymie the adoption of new ways of working "in a more resilient way" - exemplified by the Rockefeller 100 Resilient Cities campaign. Local-level government organizations are also seeking out new strategies for the adoption of resilience in managing local corruption ${ }^{32}$ through forms of community engagement ${ }^{33}$ and weathering

31 Yossi Sheffi, The Resilient Enterprise: Overcoming Vulnerability for Competitive Advantage (Cambridge, MA: MIT Press, 2005); Yossi Sheffi, The Power of Resilience: How the Best Companies Manage the Unexpected (Cambridge, MA: MIT Press, 2015).

32 Rabiul Islam, Greg Walkerden, and Marco Amati, "Households' Experience of Local Government during Recovery from Cyclones in Coastal Bangladesh: Resilience, Equity, and Corruption," Natural Hazards 85, no. 1 (2017): 361-378.

33 Deborah Platts-Fowler and David Robinson, "Community Resilience: A Policy Tool for Local Government?" Local Government Studies 42, no. 5 (2016): 762-784, https://doi.org/10.1080/03003930.2016.1186653. 
austerity $^{34}$ or managing competing interests in island communities. ${ }^{35}$

In all of these, and more, diverse encounters flexibility in the operational interpretations of "resilience as governance" provides insight into the strategic adoption of constraints or incentives influencing the conditions of possibility for human conduct, both implied and enacted through the interplay of complementary rules and practices. These constraints or incentives are enacted formally and informally, for example, in individuals' cognitive conduct in their daily lives, i.e., informal socially constructed 'cultural' values ${ }^{36}$ and as diverse formal contractual relations between individuals, markets and, organizations, ${ }^{37}$ manifest in governance. "Being resilient" presents a concurrent stream of work in synch with the operational instrumental protocols and practices, but this emergent arena is not the governance of external risk, hazard, or threat; instead, emphasizing the conduct and immanent vulnerabilities of the resilient subject as a legitimate arena of governance. This amorphous evolution of a contested concept has stimulated a vigorous critique of resilience, which must also be addressed.

\section{The Critique of Resilience}

Central to the emergence of the critique of resilience has been the drive to problematize resilience properly. A body of critical scholarship has built on post-structural readings of both biopolitical ${ }^{38}$ and neoliberal ${ }^{39}$ narratives. Indeed, so vociferous has been the critique emerging from these fields that resilience has been decried as politically debased and intellectually exhausted, creating "pernicious forms of subjugation it burdens people with, its deceitful emancipatory claims that force people to embrace their servitude as though it were their liberation, and the lack of imagination the resiliently minded possess in terms of transforming the world for the better." ${ }^{40}$ Yet, the advance of resilience thinking and prac-

34 Vivien Lowndes and Kerry McCaughie, "Weathering the Perfect Storm? Austerity and Institutional Resilience in Local Government," Policy \& Politics 41, no. 4 (2013), 533549, https://doi.org/10.1332/030557312X655747.

35 David Chandler and Jonathan Pugh, "Islands of Relationality and Resilience: The Shifting Stakes of the Anthropocene," Area 52, no 1 (2020): 65-72, https://doi.org/10.1111/area.12459.

36 Avner Greif and Joel Mokyr, "Cognitive Rules, Institutions, and Economic Growth: Douglass North and Beyond," Journal of Institutional Economics 13, no. 1 (2017): 2552, https://doi.org/10.1017/S1744137416000370.

37 Julio Faundez, "Douglass North's Theory of Institutions: Lessons for Law and Development," Hague Journal on the Rule of Law 8, no. 2 (2016): 373-419.

38 Chris Zebrowski, "Governing the Network Society: A Biopolitical Critique of Resilience," Political Perspectives 3, no. 1 (2009), http://www.political perspectives.org.uk/wp-content/uploads/2010/08/Vol3-1-2009-4.pdf.

39 Jonathan Joseph, "Resilience as Embedded Neoliberalism: A Governmentality Approach," Resilience 1, no. 1 (2013): 38-52, https://doi.org/10.1080/21693293.20 13.765741.

40 Brad Evans and Julian Reid, "Exhausted by Resilience: Response to the Commentaries," Resilience 3, no. 2 (2015): 154-159, quote on p. 154. 
tice has not been slowed by this critique; instead, it has accelerated. Critics have wrestled with this problem, Walker and Cooper suggesting that the resilience episteme empowers reabsorption of critique into "an agenda of resource management that collapses ecological crisis into the creative destruction of a truly Hayekian financial order." ${ }^{41}$ The case for a counter-systemic critique is not made here on ontological grounds, as the logic of critique underpinning this approach requires the neoliberal system and its concomitant assumption of undisputed liberal institutions to hold its shape. When such assumptions are made, they tend towards the narrowing of focus in the pursuit of generating a totality for the purpose of critique, i.e., resilience is. I argue that this defies the contingent obligations of a polysemous and relational assemblage-in the act of defining resilience by what it is, the boundaries and permeating oscillations of meaning through which resilience is manifest are blurred-to be better revealed by interrogation of how it is enacted. The neoliberal critique seeks delineation to assert intersection or interpenetration at critical moments where they should describe and analyze interplay in the relative and situated context of the specific encounter through the complementary rules and practices of its operation. Many such critiques of resilience through the lens of neoliberalism reflect an ambient form of melancholic attachment to the radical politics of pre-1989 socialism, also dependent on the liberal ontology for its raison d'être. ${ }^{42}$ Such critique appears to actively capitulate to the "end of history" as empowering an inevitable reabsorption cycle, where any possibility of a progressive or democratic alternative surviving within capitalism is impossible. Any progressive change is to be predictively co-opted by an amorphous and open-ended process of neoliberalization.

$I$ argue this is too narrow a reading for the onto-politics of resilience, whose future is not yet determinable. For good or bad, each encounter with resilience opens new possibilities. Perhaps the greatest mistake is to actively foreclose or disavow both the concept itself and the variations in politics - forms of knowing, doing, and acting - that resilience offers to us. There is no contesting that there is potential for resilience to be a destructive influence, yet there are also possibilities for it to open new spaces for reclamation of politics by engaged citizens. These are tangible, empirically verifiable, and relevant to our wider project of interrogating what democratic politics has been, is now, and may become in future. $^{43}$

41 Jeremy Walker and Melinda Cooper, "Genealogies of Resilience: From Systems Ecology to the Political Economy of Crisis Adaptation," Security Dialogue 42, no. 2 (2011): 143-160, https://doi.org/10.1177\%2F0967010611399616, quote on p. 157.

42 This melancholy of the left might be due to an "over-attachment to a past political identity, even in its failure" for whom progressive change is only meaningful if tied to the advancement of their ideological limitations. Neda Atanasoski and Kalindi Vora, "Postsocialist Politics and the Ends of Revolution," Journal for the Study of Race, Nation and Culture 24 (2018): 139-154, quote on p. 143, https://doi.org/ narrowing of focus 10.1080/13504630.2017.1321712.

43 See for example Bruce E. Goldstein, ed., Collaborative Resilience: Moving Through Crisis to Opportunity (Cambridge, MA: MIT Press, 2011); and Bruce Evan Goldstein, 
It is difficult to contest the evidence that resilience as governance does not apply to all citizens evenly and may be instrumental in deepening existing and creating new inequalities - i.e. "resilience for whom?" $44,45,46,47$ Despite raising troubling issues in the instrumentalist interpretation of resilience the critical narrative has relied heavily on a post-structuralist reading of power that does not integrate well with the changing dynamics of governance, nor the 'onto-political' shift underpinning the spread of resilience in policy and practice. Discussion has begun more recently to move away from openly antagonistic criticism towards a proactive discussion of resilience as a complex assemblage read in the context of a destabilized liberal ontology. ${ }^{48}$ This approach opens the possibility of resilience as more than a new skin for old wine tied to the critique of neoliberalism, ${ }^{49}$ opening access to a broader rethinking of power itself, the relations of force emerging from resilience thinking, and the conditions of possibility for a different 'politics' to grow. Through this engagement with the ontology underpinning politics, the concept is now being seen, for good or ill, as part of an ongoing, fundamental shift in the way we "know things" about a complex world in the emerging Anthropocene. ${ }^{50,51}$

Where the neoliberal critique has failed to deal with the underpinning ontological challenges to politics and science more broadly, this approach rather embraces the destabilization of traditional boundaries of knowledge: "The Anthropocene enables 'a movement of thought that is truly counter-systemic' because

Anne Taufen Wessells, Raul Lejano, and William Butler, "Narrating Resilience: Transforming Urban Systems Through Collaborative Storytelling," Urban Studies 52, no. 7 (2015): 1285-1303, https://doi.org/10.1177/0042098013505653.

44 Raven Cretney, "Resilience for Whom? Emerging Critical Geographies of Socio-Ecological Resilience," Geography Compass 8, no. 9 (2014): 627-640, https://doi.org/10.11 11/gec3.12154.

45 Amanda Fitzgerald, "Querying the Resilient Local Authority: The Question of 'Resilience for Whom?'," Local Government Studies 44, no. 6 (2018): 788-806, https://doi.org/10.1080/03003930.2018.1473767.

46 Hugo Herrera, "Resilience for Whom? The Problem Structuring Process of the Resilience Analysis," Sustainability 9, no. 7 (2017), 1196, https://doi.org/10.3390/su90 71196.

47 Sara Meerow and Joshua P. Newell, "Urban Resilience for Whom, What, When, Where, and Why?" Urban Geography 40, no. 3 (2019): 309-329, https://doi.org/ 10.1080/02723638.2016.1206395.

48 David Chandler, Stephanie Wakefield, and Kevin Grove, eds., Resilience in the Anthropocene: Governance and Politics at the End of the World (London: Routledge, 2020).

49 Marc Welsh, "Resilience and Responsibility: Governing Uncertainty in a Complex World," The Geographical Journal 180, no. 1 (2014): 15-26, https://doi.org/10.1111/ geoj.12012.

50 Chandler, Grove, and Wakefield, eds., Resilience in the Anthropocene.

51 Kevin Grove and David Chandler, "Introduction: Resilience and the Anthropocene: The Stakes of 'Renaturalising' Politics," Resilience 5, no. 2 (2017): 79-91, https://doi.org/ 10.1080/21693293.2016.1241476. 
time and space enter and thereby destabilize the idea of a separate 'inside.'" 52 By destabilizing the notion of 'inside' and 'outside,' the Kantian division between the human and the natural world through the artifice of reason is collapsed. ${ }^{53}$ This allows for a renegotiation of institutional order at the level of subject-object, renegotiating the boundaries of sentient life itself within the confines of a moral custodianship of our ecological capacity to exist. In terms of a socio-ecological reading of resilience, the social order of the Anthropocene has moved out of the 'exploitation' and 'conservation' phases where the system can be optimized for those best suited to its current configuration and past the tipping point into the release and reorganization phase - or the 'back loop.' ${ }^{54}$ Chandler has suggested that the Anthropocene "is not just another problem or crisis to be 'solved' or 'bounced-back' from or 'recouped' but rather a sign that modernity was a false promise of salvation, one that has brought us to the brink of destruction." 55 Indeed, the concept of "dwelling in the ruins" ${ }^{56}$ moves beyond the prediction of a darker side to resilience and instead seeks to explore the contemporary 'ruins,' where by "biopolitical doubling, we now manage other life to secure human life." 57 This argument suggests that managing the effects of the exigencies of neoliberal rule-rather than the causes-resilient governance creates a cascade of deferment "papering over the cracks" but not delivering solutions. ${ }^{58}$ Rather than critically engaging with resilience as a means for progressive politics in the space between nature and human action, this is pre-emptively presented as the death knell of "coercive resilience" as a system of governance due to exposure of its failure to deal with anthropocentric accountability in the light of a collapsing modernist project. Thus, this "coerced resilience" is "created as a result of anthropogenic inputs such as labour, energy and technology, rather than supplied by the ecological system itself. In the context of production systems, coercion of resilience enables the maintenance of high levels of production," ${ }^{59}$ which ends in a counter-productive deepening of crises wherever resilience is adopted.

52 Chandler, Grove, and Wakefield, eds., Resilience in the Anthropocene, 82.

53 Chandler, Grove, and Wakefield, eds., Resilience in the Anthropocene.

54 Stephanie Wakefield, "Inhabiting the Anthropocene Back Loop," Resilience 6, no. 2 (2018): 77-94.

55 David Chandler, "Resilience and the End(s) of the Politics of Adaptation," Resilience 7, no. 3 (2019): 304-313, https://doi.org/10.1080/21693293.2019.1605660.

56 Stephanie Wakefield, "Infrastructures of Liberal Life: From Modernity and Progress to Resilience and Ruins," Geography Compass 12, no. 7 (2018): 123-177, https://doi.org/ 10.1111/gec3.12377.

57 Stephanie Wakefield and Bruce Braun, "Oystertecture: Infrastructure, Profanation and the Sacred Figure of the Human," in Infrastructure, Environment, and Life in the Anthropocene, ed. Kregg Hetherington (Durham, NC: Duke University Press, 2018), 193-215, https://doi.org/10.1215/9781478002567-012.

58 Chandler, Grove, and Wakefield, eds., Resilience in the Anthropocene, 83.

59 Lucy Rist, Adam Felton, Magnus Nyström, et al., "Applying Resilience Thinking to Production Ecosystems," Ecosphere 5, no. 6 (2014), 73, https://doi.org/10.1890/ES1300330.1 , quote on p. 3. 


\section{The Limits of Critique: Emergence, Complexity and Positive Politics}

Emergence and complexity are important aspects of the approach to resilience discussed in this article, as they relate to the nature of the fundamental ontopolitical shift implied by resilience as governance and open ways to address the pessimism of the critique discussed above. When thought of as a shift in the 'onto-politics' 60 of our time, i.e., the politics of 'being, ${ }^{61}$ resilience enacted represents a manifold transformation in the rules of the game underpinning social interactions. It also potentially transforms the political subject and the conditions of possibility for politics, as understood by the socio-contractual relationships that have defined modernity. The subject and the structure become unfixed, destabilized by the uncertainty of crisis and the need to govern the effects of these crises when they arise without disrupting the orderly flow of capital or undermining the fabric of social order.

The critique identifies conceptual fault lines between the theory and enactment of resilience but rarely offers progressive solutions as the decentralized enactment as governance leads to different articulations of its emergent ontopolitics. Emergence becomes a problem for the critique in aligning the output of problematization with a program of meaningful action to influence a better kind of resilience. Contemporary scientific empiricism requires hard certainties with optimized outputs and outcomes, but the transformation we are engaged in has not 'happened' so much as they are woven into a temporal cycle with perpetually uncertain results. Multitudes of variables are in play and cannot be exhaustively listed, as they range, and are not limited to: the emergent Anthropocene and concomitant climate crisis; the exigencies of rampant free-market capital; the reordering of human interactions emerging from artificial intelligence, machine learning and algorithmic forms of governance; creeping authoritarianism in 'third-way' politics and the wider reformation of the liberal political order emerging from the prematurely proclaimed "end of history." Yet history continues to accrue new complexities in defiance of such proclamations, weaving evermore-complex assemblages of interdependency, which I have elsewhere called a process of interplay. ${ }^{62}$ The ongoing changes cannot be neatly boiled down to a disciplinary approach, a singular canon of theory, method, nor any single mode of critique, for they are not neatly diachronic or bounded in nature as rational reductionism or deductive science would prefer. Rather transformation has become an emergence of the interregnum, a porous ill-defined new normal from

60 There are several critical engagements with this concept emerging in recent research, of particular note being David Chandler, Ontopolitics in the Anthropocene: An Introduction to Mapping, Sensing and Hacking (London: Routledge, 2018).

61 David Chandler and Julian Reid, "'Being in Being': Contesting the Ontopolitics of Indigeneity," The European Legacy 23, no. 3 (2018): 251-268, https://doi.org/10.1080/ 10848770.2017.1420284.

62 Peter Rogers, Resilience \& the City: Change, (Dis)Order and Disaster (Farnham: Ashgate, 2012). 
which one must attempt to engage with the complexities of a shifting 'onto-politics' as they move towards an uncertain end reconfiguration.

Engagement with the onto-politics of resilience aims to open the black box of unintended consequences for pragmatic appraisal of its complementary rules and practices. Though still in development as a coherent project, this approach challenges the assumed "resilience dividend." ${ }^{63}$ In asking if changes empowered by resilience are worthy of institutionalization into the logic of our social order or undermine the core strength of liberal democratic politics, this does not reject resilience but seeks to align the configuration of onto-politics towards an inclusive, democratizing project. The goal is not to seek a particular rational 'truth' of resilience as it appears in rational models or normative framings of the idea. Rather to harness these diverse encounters with resilience to challenge the normative institutions (i.e., "rules of the game") emerging from its enactment, and to foster them towards collaborative and participatory practices that are more complementary to liberal democratic first-order principles than to the exigencies of market-oriented and algorithmic systems of governing. This tests a (more) reflexive theorization of practical interventions resilience empowers in the governance of everyday life. At the level of institutional rules and practices, it is a challenge to materialist conceptions of knowing, post-structuralist critique, and the promissory politics of citizen-state relations where resilience informs redrawn parameters within contractual expectations, e.g., tied to notions of citizenship, rights, and responsibilities.

A shift empowered by the spread of resilience as an institutional pillar of governance requires a rethinking of the constraints underpinning what government is and what governance does. This demands that we pay attention to the "politics of being" underpinning the governance of problematic populations in times of perpetual crisis, and more so how it is enacted. These enactment strategies have significant implications for how the socio-contractual relationships between citizen and state are to play out. The institutionalized "rules of the game" which empower contractual interactions between individuals, organizations and markets influence in turn what forms of expectations we have of our core democratic institutions, such as human rights, property rights, and, more broadly, the formal and informal relations of force by which an order for everyday life is established. This informs the conditions of possibility for a resilient form of social order, for resilient individuals to act within complex, interdependent systems of influence. Bearing these factors in mind, the emergence and complexity problems require a careful and thoughtful problematization. However, that problematization must have space for a positive outcome if it is to remain progressive and, more importantly, accessible to practitioners in the situated context of their specific organization and its remit.

63 Judith Rodin, The Resilience Dividend: Being Strong in a World Where Things Go Wrong (Philadelphia, PA: Public Affairs, 2014). 


\section{The Problem with Problematization}

I have argued that if problematization is to lead to positive outcomes, becoming more resilient and governing for resilience should be engaged with critically but positively. The biopolitical and neoliberal critiques of resilience appear to struggle with how to explain the ontological tension between what resilience was thought to be and what it is becoming. The onto-politics of a resilient social order expressly challenges some of the fundamental assumptions enmeshed within the onto-politics of modernity - including traditional programs of opposition or resistance and boundaries between human and natural systems. ${ }^{64}$ Resilience may represent a more nuanced shift in the underlying principles and mechanisms of governance than a simple reproduction of economic governmentalities neoliberalism allows for. The framed focus of governance from the causes of social problems to the management of their effects, or as Aradau suggests "from the promise of security to the non-promise of resilience" 65 might be better understood within the context of the ontological interplay between configurations of resilience.

This promissory shift represents an onto-political change in the relationship between the citizen-state-market. Whilst the state retains an implied responsibility for the survival of the citizen-subject under a 'neoliberal' model of social order, contractual freedoms are ceded to a curated market, incentivized choice from within preferred option sets are rationally refined as a means of open access to privileges. However, the automatic balancing of the system is an impolite fiction. Combined with ongoing transformations in governance practice, the incentive structure for "becoming resilient" prioritizes citizen responsibilities to participate in the survival of not just the "body politic" but the entire planet. In this sense, it can be read as a call for individuals to take personal responsibility with an intent to engage, but often enacted problematically where elements of coercion dominate the collaborative and participatory potential of an emergent onto-politics of resilience.

Problematizing the complexity woven through the emergence of a "resilient social order" requires us to draw on a number of encounters with the resilience concept. It is uncertain if there even is a singular ontology underpinning resilience nor if this is inherently an ontology of transformation. Rather than fixity or security, resilience cannot hold fixed concepts of access to rights and privileges that have traditionally underpinned ordering institutions. Liberal and democratic philosophies of the social contract, the rule of law, human rights (broadly), and the presence of enforceable expectations regarding contractual protections of basic rights-for example, access to organizations, property ownership, exchanges and service provisions (more narrowly) - can be useful as a form of crit-

64 Here I am drawing on Blaser's reading of political ontology. Mario Blaser, "Ontological Conflicts and the Stories of Peoples in Spite of Europe," Current Anthropology 54, no. 5 (October 2013): 547-568, https://doi.org/10.1086/672270.

65 Aradau, "The Promise of Security," 75. 
ical engagement but have to date been framed poorly by biopolitical and neoliberal theorizations. This is also where the differing conceptions of power underpinning a new institutional economics approach clashes most with the poststructuralist readings of power tied to a (dated) critique of capitalism. The pursuit of a unified ideologically coherent ontology is not encouraging in such conditions. Indeed, it does not seem useful or desirable in the face of so many versions of resilience deployed in so many different ways.

As there are many permutations of resilience drawn from a rich history, this concept must be critically engaged with not as unified, but as a multiplicity with negative and positive configurations. This is essential if we are to understand the influence and importance of resilience as an institutional rule adding constraints or incentives to human action. As such, while the framework of institutions as processual can align notionally with the discussion of biopolitics and governmentality, the way in which they engage with access to privilege and the use of violence as a driver of social ordering is different and should be interrogated more deeply.

If resilience is a concept best understood as "in the process of becoming" in statu nascendi ${ }^{66}$ - then one can appreciate the multitude of encounters as a complex diffusion within and through which the interplay configures distinct yet mutually permeable conditions of possibility. The effect of these conditions of possibility, enacted as relations of force, will be encountered differently in each situated context. Sovereign power still exists but no longer promises security in traditionally understood terms; the contract is instead coordinated by agentbased decision-making amongst conditions of possibility configured by a blend of sovereign intent, individual agency and market-configured options layered in complex assemblages of contractual relations. Disciplinary power is not confined to the legitimate use of violence by sovereign actors of 'the state' but rather distributed through locally encountered pre-configurations of the options from which one can choose, embedded in sovereign power but transformed in statu nascendi by increasingly impersonal, automated forms of algorithmic translation. Traditional limits of violence are blurred and blended with the impersonal stochastic configuration of choices, rendered legible through the concomitant interface by which the individual gains access to their choices. Increasingly the blurring of such distinctions by the adoption of algorithmic governance principles leads to more impersonal, less visible relations of force, where access to privileges is increasingly limited by algorithmic curation, rather than 'opened' by market-led freedom of choice. Sovereign power does not impose order on the market but rather relies on the market to configure access to privilege based on automatically balancing egalitarian populism, led by the abstract, rational, calculative individual subject.

66 Peter Rogers, "The Etymology and Genealogy of a Contested Concept," in The Routledge Handbook of International Resilience, ed. David Chandler and Jon Coaffee (Abingdon, UK: Routledge, 2017), 13-25. 
This is a form of 'onto-politics' that challenges the reliance of Foucault on distinctions of 'sovereign' and 'population' as the key loci of violence. It also challenges North's linear reading of social order as defined by politics, economic, and social relations, where the dynamics of these exchanges are limited to the legitimate use of violence. Neither adequately problematize the complexity of context or the willing submersion of rationally neurotic citizens, subjectified by the legacy of cold war theory and public choice economics as complicit in the coproduction of new 'softer' forms of non-material violence, informing the revision of liberalism. Nor do they adequately address the emergence of a 'flatter' ethics of the Anthropocene, collapsing human nature distinctions in ways that directly challenge "sacral faith" in the fundamentalism of finance. ${ }^{67}$ Such forms of power are essentially iterative and emergent, but not static, as they operate within the conditions of possibility for individual cognition - i.e., the "freedom to choose" in competition with the "right to life." If we assume that market institutional logics have increasingly subsumed those democratic logic implied by the "public sphere" -through, for example, the rise of algorithmic governance as a means for editing access to privileges - then this period of transformation would see institutions of democracy become less stable, even as market-oriented institutions become more influential and less accountable to sovereign power. We have seen some early signs that this is an active feature of the interregnum in recent years, with questions over the legitimacy of the democratic process emerging even in the "land of the free," following the 2008 financial crisis and the 2016 presidential election. Yet, given the complexity of the resilience conundrum and the permeation of the onto-politics of resilience into governance as an institutional principle of ordering a positive critique might yet encourage a return to the more emancipatory conditions of possibility immanent to the discourse of resilient transformation as an enactment of altruism.

\section{Positive Critique over Open-ended Problematization}

Problematizations are a good way to engage with the emergent, the contingent, and the complex. As a strategy for researchers, it empowers us to systematically identify and examine potential problems and identify where theoretical assumptions may have become outdated. ${ }^{68}$ For some researchers, problematizations offer a means to develop a "history of the present," 69,70 tracing historical antecedents of particular problems relative to the configuration of key variables, such as

67 Luca Mavelli, "Neoliberalism as Religion: Sacralization of the Market and Post-truth Politics," International Political Sociology 14, no. 1 (2020): 57-76, https://doi.org/ 10.1093/ips/olz021.

68 Manos Gkeredakis and Panos Constantinides, "Phenomenon-based Problematization: Coordinating in the Digital Era," Information and Organization 29, no. 3 (2019), 100254, https://doi.org/10.1016/j.infoandorg.2019.100254.

69 Stuart Elden, Mapping the Present: Heidegger, Foucault and the Project of a Spatial History (London: Bloomsbury, 2002).

70 Garland, "What Is a "History of the Present"?" 
moral, political, economic, military, geopolitical or juridical institutions and the practices of organizations. ${ }^{71}$ They also address how certain individuals, populations, and forms of conduct become seen as "problems to be solved" in these relative contexts. Using this approach, problematization helps explore and explain the interplay of technologies, authorities, subjectivities, and strategies in complex systems. ${ }^{72}$

The 'problem' with a problematization of resilience is, first, the diversity of applications to which it can be put, or what I have called the diversity of 'encounters' one can have, ${ }^{73}$ and second, the tendency toward criticism over critique when engaging with ontological challenges to pre-interregnum practices of critique. There is a tendency to imply diachronic boundaries embedded in a historicism that reifies absolutist or authoritarian readings of power and sovereignty tied to classical liberal concepts of contractual rights and obligations. If outdated and outpaced by social and technological challenges to social ordering that could not have been thought of in the enlightenment or during industrial revolutions, these concepts are likely to need revision. Overly bio-political approaches have struggled to transcend this legacy contributing many detailed etymologies, taxonomies and genealogical appraisals of resilience but failing to grasp the significance of the contextual encounter as a space to bring theory and empirical research together with policy and practice. The Anthropocene approach has opened the door to a positive reading but struggled to articulate a progressive path for governance.

Where encounters seek to harness the 'polysemic'74 nature of resilience, they initially encouraged the treatment of resilience along disciplinary grounds, fueling a host of narrower literature reviews. ${ }^{75,76,77}$ Traction appeared to be gained in areas of disaster and crisis management, sustainable development, disaster risk reduction, hazard mitigation, and security related to terrorism, ${ }^{78}$ but

71 Nikolas Rose, Governing the Soul: The Shaping of the Private Self (New York: Routledge, 1990).

72 Rose, Governing the Soul, pp. xi-xii.

73 Rogers, Resilience \& the City.

74 For an overview of resilience and polysemy see Reghezza-Zitt, et al., "What Resilience Is Not: Uses and Abuses"; and Rogers, "The Etymology and Genealogy of a Contested Concept."

75 Ran Bhamra, Samir Dani, and Kevin Burnard, "Resilience: The Concept, A Literature Review and Future Directions," International Journal of Production Research 49, no. 18 (2011): 5375-5393, https://doi.org/10.1080/00207543.2011.563826.

76 Patrick Martin-Breen and J. Marty Anderies, "Resilience: A Literature Review," Institute of Development Studies, 2011, https://opendocs.ids.ac.uk/opendocs/handle/ 20.500.12413/3692.

77 Adrian DuPlesis VanBreda, Resilience Theory: A Literature Review (Pretoria, South Africa: South African Military Health Service, 2011).

78 Jon Coaffee and David Murakami Wood, "Security is Coming Home: Rethinking Scale and Constructing Resilience in the Global Urban Response to Terrorist Risk," Interna- 
have reappeared in areas as diverse as financialization, ${ }^{79}$ housing, ${ }^{80}$ and more recently in critical discussions of algorithmic governance. ${ }^{81}$ The academic response to the emergence of the resilience concept was overwhelmingly critical; 82 yet, this has not slowed the adoption of resilience as powerful rhetoric in policy, as an influential core business function of organizations in public and private life and as a challenge to our understanding of contractual relationships between citizens, state and markets.

Approaching resilience as a form of 'onto-politics' opens this up to further detailed exploration. Chandler presents the onto-political as more than "the assertion of a new reality in opposition to an old account." If one engages with the institution of resilience productively, it should be possible to logically render sensible the relative connections between the dividing and sorting practices involved in managing problematic populations and the logic of the underpinning incentive structures; both in terms of the masking and coercive tendencies of resilience done poorly and the emancipatory and democratizing potential as a form of collaborative, participatory politics. This aligns well with the study of resilience, as it has appeared in many of these domains throughout its ongoing evolution. In the game-theoretic terms of institutional economics, resilience as an effective institution should raise the benefits of cooperative solutions or increase the cost of non-conformance to the underlying logic. In these terms, the underlying onto-politics of resilience should be of great interest to us. This is where the genealogical problematization of the concept becomes important to consider in more depth, but the pessimistic lens placed upon current critique using emergence and complexity in the Anthropocene tend to a priori foreclose the possibility of a progressive politics existing.

\section{Conclusion}

While skeptical of the pessimism inherent in much of the critique, one cannot say that the concerns are unfounded. Problems are clearly present in the piecemeal and partial nature of resilient governance, with many articulations of resilience struggling to find purchase amongst the path dependency of risk-averse

tional Relations, 20, no. 4 (2006): 503-517, https://doi.org/10.1177/00471178060694 16.

79 lain Hardie, Financialization and Government Borrowing Capacity in Emerging Markets (London and New York: Palgrave Macmillan, 2012).

80 Graham Squires and lain White, "Resilience and Housing Markets: Who Is It Really for?" Land Use Policy 81 (2019): 167-174, https://doi.org/10.1016/j.landusepol.20 18.10.018.

81 David Chandler, "Algorithmic Governance: Actor Networks and Machinic Correlation," Western Political Science Association (WPSA) annual convention "The Politics of Climate Change," San Diego, California, 2019, accessed October 15, 2020, www.wpsa net.org/papers/docs/WPSA\%20algorithmic\%20governance.pdf.

82 Julian Reid, "The Disastrous and Politically Debased Subject of Resilience," Development Dialogue 58, no. 1 (2012): 67-79. 
governance organizations and subject to exploitation for wealth creation by private sector organizations. The implications of greater coordination between algorithmic and surveillance systems within governance through the immediate requirements of crises are a very real threat to the progressive politics I have suggested. COVID-19 tracking apps have been at the bleeding edge of a renegotiation of the institutional relations of force between citizen-state-market demonstrating the fragility of traditional socio-contractual assumptions during the emergent interregnum. Such examples must be a future focus for researchers of resilience less concerned with what resilience is and more concerned with what resilience does. ${ }^{83}$ This brings our attention back to the operant enactment of resilience within existing and emergent incentive structures for the purpose of understanding the institutional logic of governance in practice.

The polysemous nature of resilience encourages us to appreciate the contextual embedding of the concept where it is encountered, ${ }^{84}$ and there are many encounters with resilience to explore that expose what resilience does in different configurations. As Grove states, "resilience is slowly transforming thought and practice in ways that often fly under the radar of conventional forms of analysis and reflection both critical and applied." ${ }^{85}$ Balancing the current resilience concept with its institutionalization helps us fly low enough to see and determine the articulation of shifting contractual relationships and their complementary rules and practices. Drawing on historical antecedents of the concept and current critical articulations expose this need for a more balanced understanding of the potential public good, but with a sober awareness of the dangers posed by resilience done badly.

\section{Disclaimer}

The views expressed are solely those of the author and do not represent official views of the PfP Consortium of Defense Academies and Security Studies Institutes, participating organizations, or the Consortium's editors.

\section{Acknowledgment}

Connections: The Quarterly Journal, Vol. 19, 2020 is supported by the United States government.

\section{About the Author}

Peter Rogers is a Senior Lecturer in Sociology at Macquarie University, Australia. He is the author of The Everyday Resilience of the City (with Jon Coaffee and David Murakami-Wood) and Resilience \& the City: Change, (Dis)Order and Disaster. E-mail: Peter.rogers@mq.edu.au

83 Kevin Grove, Resilience (Key Ideas in Geography) (Abingdon, UK: Routledge, 2018), p. 4.

84 Rogers, "The Etymology and Genealogy of a Contested Concept."

85 Grove, Resilience, p. 4. 